\title{
Functionalisation of Carbon-Fluorine Bonds with Main Group Reagents
}

Wenyi Chen, Clare Bakewell, Mark R. Crimmin*

Department of Chemistry, Imperial College London, South Kensington, SW7 2AZ, UK. m.crimmin@imperial.ac.uk

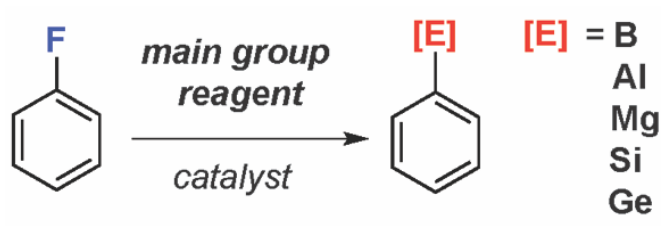

\begin{abstract}
Synthetic approaches to produce reactive chemical building blocks from fluorinated molecules by the functionalization of the carbon-fluorine bonds with main group reagents are reviewed. The reaction types can be categorized as (i) the formal 1,2-addition of $C-F$ bonds across Si-Si, B-B or Mg-Mg bonds (ii) the oxidative addition of $\mathrm{C}-\mathrm{F}$ bonds to Si(II), Ge(II) and Al(I) centres and (iii) the dehydrogenative coupling of $C-F$ bonds with $A /-H$ or $B-H$ bonds. Many of the advances have emerged between 2015-2016 and are largely focused upon aromatic substrates that contain $s p^{2} C-F$ bonds.
\end{abstract}

\section{Table of Contents}

1. Introduction

2. C-F Borylation of Aromatic $\mathrm{sp}^{2} \mathrm{C}-\mathrm{F}$ Bonds

2.1 Rhodium Catalysis

2.2 Nickel Catalysis

3. C-F Alumination of $\mathrm{sp}^{2} \mathrm{C}-\mathrm{F}$ Aromatic and $\mathrm{sp}^{3} \mathrm{C}-\mathrm{F}$ Aliphatic Bonds

4. C-F Silylation and Germylation of Aromatic $\mathrm{sp}^{2} \mathrm{C}-\mathrm{F}$ Bonds

5. C-F Magnesiation of Aromatic $\mathrm{sp}^{2} \mathrm{C}-\mathrm{F}$ Bonds

6. C-F Silylation and Borylation of Alkenes

7. Conclusions and Future Directions

8. References

Keywords: Fluorine, carbon-fluorine, Functionalisation, Borylation, Silylation, Alumination, Magnesiation.

\section{Introduction}

The carbon-fluorine bond is the strongest single bond between carbon and any element. As a result, while fluorocarbons are often persistent in the environment they find uses as polymers, liquid crystals, surfactants, agrochemicals and pharmaceuticals. It has been estimated that $20 \%$ of pharmaceuticals and more than $28 \%$ of contemporary agrochemicals contain at least one carbonfluorine bond. ${ }^{1,2}$ Lipitor, a blockbuster pharmaceutical used primarily in the treatment of cardiovascular disease, has become a textbook example of a fluorine containing drug. ${ }^{3}$ The 
benefits of fluorine to medicinal and agrochemical programmes are clear: (i) modification of $p K a$, (ii) modification of liphophilicity, (iii) improved active site binding due to non-covalent interactions, and (iv) blocking of metabolism pathways by preventing the oxidation. ${ }^{4,5}$

Two complementary synthetic approaches to introduce fluorine into small organic molecules have emerged: late-stage fluorination ${ }^{6,7}$ and evolution of fluorinated chemical building blocks. ${ }^{8,9}$ Methods for late-stage fluorination include the reaction of carbon-halogen (and to a lesser extent carbon-hydrogen) bonds with either nucleophilic or electrophilic fluorine source. This approach continues to attract attention for the preparation of ${ }^{18} \mathrm{~F}$-labelled molecules for medical imaging, ${ }^{10,11}$ and typically allows the installation of one-fluorine atom, ideally at a selected site in an functional group dense molecule (Figure 1.1).

The second approach, derivatisation of fluorinated building blocks, relies on the fact that a variety of perfluorinated or partially fluorinated hydrocarbons are available on industrial scales. For example, fluorinated aromatics are produced by the fluorination of aromatics or heteroaromatics using $\mathrm{CoF}_{3}$ (Fowler process). ${ }^{12}$ While fluoroalkenes are important intermediates in the polymer industry (e.g production of Teflon), hydrofluorocarbons (HFCs) are produced on scale for use as refrigerants. Catalytic methods have been sought that selectively activate one or more carbonfluorine bonds in these starting materials to access new fluorinated building blocks that can be used directly in synthesis. The method often produces final products with more than one fluorine atom and by developing selective methods there is the potential to use these building blocks to control the number and position of fluorine atoms in a desired synthetic target (Figure 1.1).

Figure 1.1 Synthetic approaches to introduce fluorine into organic moleules (exemplified for $\mathrm{sp}^{2} \mathrm{C}-\mathrm{F}$ bonds of aromatics)

Late-Stage Fluorination

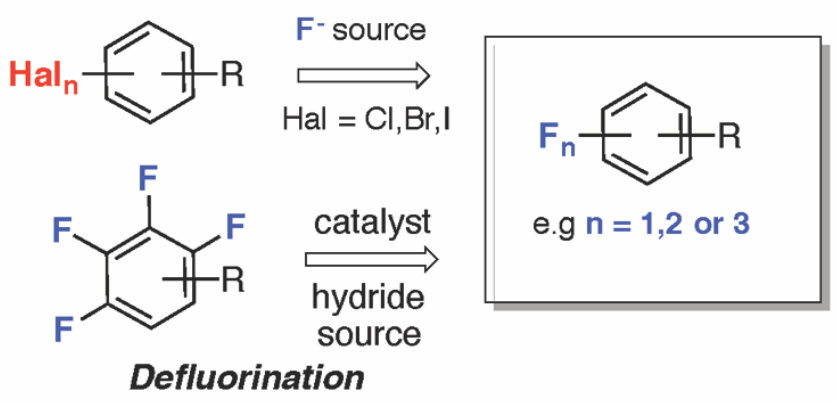

The majority of the catalytic systems developed effect either carbon-hydrogen bond formation (hydrodefluorination) or carbon-carbon bond formation (cross-coupling) from carbon-fluorine bonds. As a result, the building blocks that are made from these "inert" starting materials are often unreactive themselves and can be difficult to modify further by synthesis. These two reaction types have been extensively reviewed before. ${ }^{8,9,13-20}$ In recent years, an alternative methodology has 
been advocated: the production of reactive chemical building blocks from simple fluorocarbons. By transforming carbon-fluorine bonds into carbon-boron, carbon-aluminium, carbon-silicon, or carbon-magnesium bonds, reactive intermediates, suitable as a point of synthetic diversification, will be obtained.

Figure 1.2 Transformation of $\mathrm{C}-\mathrm{F}$ bonds to $\mathrm{C}-\mathrm{E}(\mathrm{E}=\mathrm{B}, \mathrm{Al}, \mathrm{Si}, \mathrm{Ge}, \mathrm{Mg})$ bonds: reaction types in this review

Formal 1,2-addition

$$
\begin{gathered}
\mathrm{Ar}-\mathrm{F}+(\mathrm{RO})_{2} \mathrm{~B}-\mathrm{B}(\mathrm{OR})_{2} \stackrel{\text { catalyst }}{\longrightarrow} \mathrm{Ar}-\mathrm{B}(\mathrm{OR})_{2}+(\mathrm{RO})_{2} \mathrm{~B}-\mathrm{F} \quad \text { (eq. 1) } \\
\mathrm{Ar}-\mathrm{F}+\mathrm{Me}_{3} \mathrm{Si}-\mathrm{SiMe}_{3} \stackrel{\text { catalyst }}{\longrightarrow} \mathrm{Ar}-\mathrm{SiMe}_{3}+\mathrm{Me}_{3} \mathrm{Si}-\mathrm{F} \quad \text { (eq. 2) } \\
\mathrm{Ar}-\mathrm{F}+\mathrm{BDIMg}-\mathrm{MgBDI} \longrightarrow \mathrm{Ar}-\mathrm{MgBDI}+\mathrm{BDIMg}-\mathrm{F} \quad \text { (eq. 3) } \\
B D I=\mathbf{\kappa}^{2}\{\mathrm{ArNC}(\mathrm{Me})\}_{2} \mathrm{CH}
\end{gathered}
$$

Oxidative Addition

$$
\begin{aligned}
& \left.\mathrm{Ar}-\mathrm{F}+B D / \mathrm{Si}: \longrightarrow B^{\prime} \mathrm{Si} \dot{F}_{\mathrm{F}} \text { (eq. } 4\right)
\end{aligned}
$$

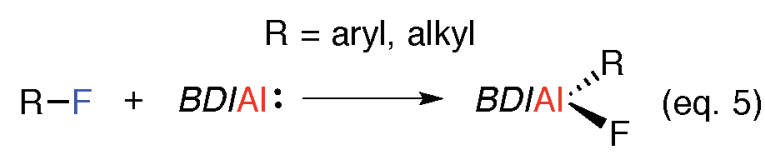

$$
\begin{aligned}
& B D I^{\prime}=\kappa^{2}-\mathrm{ArNC}(\mathrm{Me}) \mathrm{CHN}\left(\mathrm{CH}_{2}\right) \mathrm{Ar}
\end{aligned}
$$

\section{Dehydrocoupling}

$$
\begin{aligned}
& \mathrm{Ar}-\mathrm{F}+\mathrm{BDIAIH} \mathrm{H}_{2} \stackrel{\text { catalyst }}{\longrightarrow} B D I \mathrm{Al} \stackrel{*}{\mathrm{R}}_{\mathrm{F}}^{\mathrm{R}}+\mathrm{H}_{2} \text { (eq. 6) } \\
& \underset{2 \text { equiv. }}{\mathrm{Ar}-\mathrm{F}+\mathrm{H}-\mathrm{B}(\mathrm{OR})_{2}} \stackrel{\text { catalyst }}{\underset{-\mathrm{H}_{2}}{\longrightarrow}} \mathrm{Ar}-\mathrm{B}(\mathrm{OR})_{2}+(\mathrm{RO})_{2} \mathrm{~B}-\mathrm{F} \text { (eq. 7) }
\end{aligned}
$$

In this article, we review the approaches to produce reactive chemical building blocks from fluorinated molecules by functionalization of the carbon-fluorine bond. Many of the advances have emerged between 2015-2016 and are currently largely focused upon aromatic substrates that contain $\mathrm{sp}^{2} \mathrm{C}-\mathrm{F}$ bonds. The reaction types that have been developed to date include: (i) the formal 1,2-addition of carbon-fluorine bonds across $\mathrm{Si}-\mathrm{Si}, \mathrm{B}-\mathrm{B}$ or $\mathrm{Mg}-\mathrm{Mg}$ bonds often in the presence of a catalyst, (ii) the oxidative addition of carbon-fluorine bonds to low-valent main group reagents including $\mathrm{Si}(\mathrm{II}), \mathrm{Ge}(\mathrm{II})$ and $\mathrm{Al}(\mathrm{I})$ complexes and (iii) the dehydrogenative coupling of carbon-fluorine bonds with either 1 equiv. of an aluminium dihydride or 2 equiv. of a boron hydride (Figure 1.2). 


\section{C-F Borylation of Aromatic $s^{2}$ C-F Bonds}

The transformation of $\mathrm{sp}^{2} \mathrm{C}-\mathrm{F}$ bonds into $\mathrm{sp}^{2} \mathrm{C}-\mathrm{B}$ bonds has been reported for a number of perfluorinated, partially fluorinated and monofluorinated arenes. Currently, these reactions rely on the use of a stoichiometric diborane reagent, either bis(pinacolato)diborane or bis(neopentylglycolato)diborane and may be catalysed by either rhodium-phosphine complexes or a mixture of nickel-precursor, phosphine or N-heterocyclic carbene ligand, base and/or additive. The reaction results in the formation of a boronic ester along with a boron fluoride byproduct (eq. 1).

Arguably the first mention of this transformation came in $2000 .{ }^{21}$ During a report detailing the scope of carbon-hydrogen borylation, Smith and coworkers reported that $\mathrm{C}-\mathrm{F}$ borylation was observed as a minor pathway during the reaction of $\mathrm{C}_{6} \mathrm{~F}_{5} \mathrm{H}$ with $\mathrm{HBpin}$ (HBpin = pinacolborane) and a sub-stoichiometric amount $(20 \mathrm{~mol} \%)$ of $\left[\mathrm{Cp}^{*} \operatorname{Ir}\left(\mathrm{PMe}_{3}\right)(\mathrm{H})(\mathrm{Bpin})\right] .{ }^{21}$ The work that followed can broadly be divided into two approaches, (i) stoichiometric and catalytic borylation reactions of perfluoroarenes and partially fluorinated arenes mediated rhodium complexes and (ii) borylation of partially fluorinated arenes, including monofluoroarenes catalysed by mixtures containing nickel( 0$)$ precursors, primarily $\left[\mathrm{Ni}(1,5-\mathrm{COD})_{2}\right]$.

\subsection{Rhodium Catalysis}

In 2007, Marder and Perutz reported the sequential C-F activation and borylation of a series of fluorination pyridines by a rhodium(l) silyl complex. ${ }^{22}$ Reaction of $\left[\mathrm{Rh}\left(\mathrm{SiPh}_{3}\right)\left(\mathrm{PMe}_{3}\right)_{3}\right]$ with $\mathrm{C}_{5} \mathrm{~F}_{5} \mathrm{~N}$ results in the formation of $\mathrm{Ph}_{3} \mathrm{Si}-\mathrm{F}$ along with two regioisomeric rhodium products in a 3:1 ratio. The major isomer, 1, forms from $\mathrm{C}-\mathrm{F}$ bond activation of the pyridine in the 2-position, the minor 2 from reaction at the 4-position (Figure 2.1, $R=F$ ). While blocking of the 4-position with a methyl group allows complete control of the regiochemistry and exclusive formation of 1 (Figure 2.1, R = $\mathrm{Me}$ ), modifying the substrate to include a carbon-hydrogen bond at the 4-position leads to a mixture of products resulting from both carbon-hydrogen and carbon-fluorine bond activation. Subsequent reactions of the rhodium intermediates with an excess of $\mathrm{B}_{2} \mathrm{Cat}_{2}\left(\mathrm{~B}_{2} \mathrm{cat}_{2}=\right.$ bis(catecholato)diborane) at $25{ }^{\circ} \mathrm{C}$ results in slow borylation of the rhodium-carbon bond (Figure 2.1). 
Figure 2.1. Reaction of a rhodium(I) silyl complex with pentafluoropyridinesand subsequent borylation

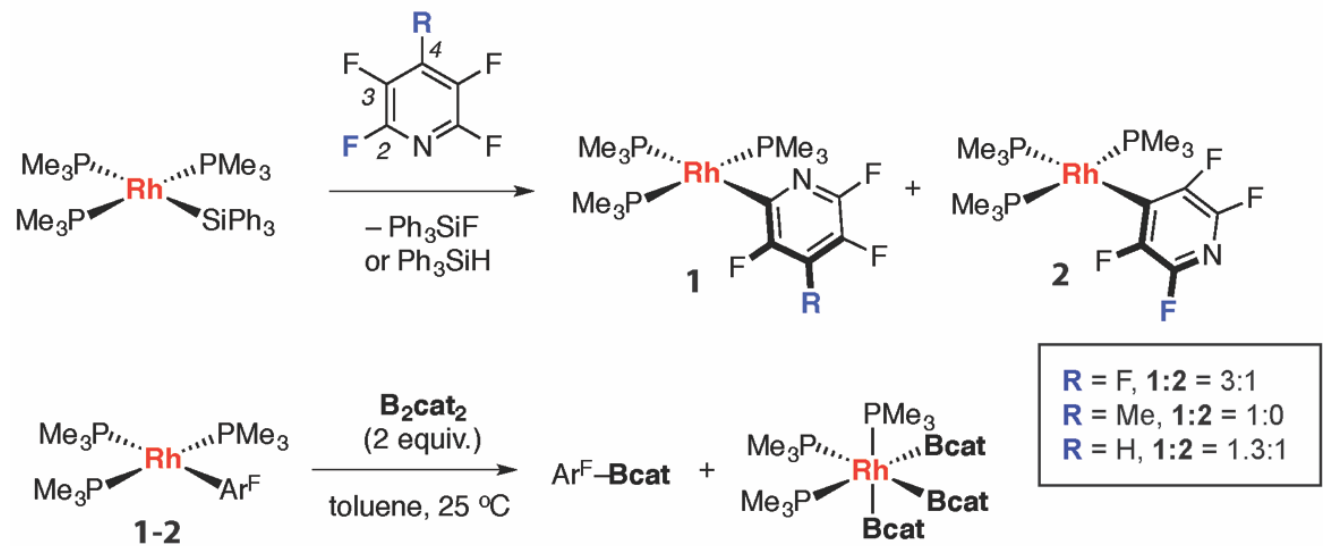

The authors conclude that catalytic turnover should be possible. In this system, however, the square-planar $\mathrm{Rh}(\mathrm{I})$ boryl complex $\left[\mathrm{Rh}(\mathrm{Bcat})\left(\mathrm{PMe}_{3}\right)_{3}\right]$, a putative intermediate reacts faster with $\mathrm{B}_{2} \mathrm{cat}_{2}$ than it does with the fluorinated substrate. The formation of $\mathrm{fac}-\left[\mathrm{Rh}(\mathrm{Bpin})_{3}\left(\mathrm{PMe}_{3}\right)_{3}\right]$ is nonreversible and this 18-complex represents a non-reactive thermodynamic sink that prevents turnover.

In 2010, through adaptation of the aforementioned synthetic procedures and modification of the phosphine ligands on rhodium, Braun and coworkers reported the in situ generation of a highly reactive 16-electron $\mathrm{Rh}(\mathrm{l})$ boryl complex, $\left[\mathrm{Rh}(\mathrm{Bpin})\left(\mathrm{PEt}_{3}\right)_{3}\right]\left(3\right.$, Figure 2.2). ${ }^{23}$ The rhodium(I) boryl, was characterised in solution by ${ }^{11} \mathrm{~B}$ and ${ }^{1} \mathrm{H}$ NMR spectroscopy, demonstrating a single ${ }^{11} \mathrm{~B}$ resonance at $\delta=46.5 \mathrm{ppm}$. Compound 3 could be generated from the reaction of either a rhodium(I) alkoxide or rhodium(I) fluoride, $\left[\mathrm{Rh}(\mathrm{X})\left(\mathrm{PEt}_{3}\right)_{3}\right]$ with $\mathrm{B}_{2} \mathrm{Pin}_{2}\left(\mathrm{X}=\mathrm{OPh}, \mathrm{F} ; \mathrm{B}_{2} \mathrm{pin}_{2}=\right.$ bis(pinacolato)diborane). fac-[Rh(Bpin $\left.)_{3}\left(\mathrm{PEt}_{3}\right)_{3}\right]$ was not observed during these reactions. The rhodium(I) boryl proved unstable. In aromatic hydrocarbons, $\mathrm{C}-\mathrm{H}$ borylation of the benzene solvent and formation of $\left[\mathrm{Rh}(\mathrm{H})\left(\mathrm{PEt}_{3}\right)_{3}\right]$ was observed.

To avoid participation of the solvent further reactions of $\mathbf{3}$ were conducted in hexamethyldisilane $\left(\mathrm{Me}_{3} \mathrm{Si}-\mathrm{SiMe}_{3}\right)$. In line with the findings of Perutz and coworkers, stoichiometric $\mathrm{C}-\mathrm{F}$ borylation of $\mathrm{C}_{5} \mathrm{~F}_{5} \mathrm{~N}$ occurs exclusively at the 2-position. Reaction with 2,3,5,6- $\mathrm{C}_{5} \mathrm{~F}_{4} \mathrm{HN}$ occurs only at the carbon-hydrogen bond with no $\mathrm{C}-\mathrm{F}$ bond activation occurring in the presence of the hydrogen atom. Catalytic turnover was achieved by reacting pentafluoropyridine with $\mathrm{B}_{2} \mathrm{pin}_{2}$ and $2.5 \mathrm{~mol} \% 3$ in hexamethyldisilane. The choice of solvent is noteworthy as Murai and coworkers have shown that this disilane itself may be used as a terminal reagent for $\mathrm{C}-\mathrm{F}$ bond silylation (see section 6 ). The product of carbon-fluorine borylation 2-Bpin $\mathrm{C}_{5} \mathrm{~F}_{4} \mathrm{~N}$ was formed as the sole regioisomeric product in $45 \%$ yield, representing a TON of 18 (Figure 2.2). 
Figure 2.2. Rhodium catalysed C-F borylation of perfluoroarenes with $\mathrm{B}_{2} \mathrm{pin}_{2}$

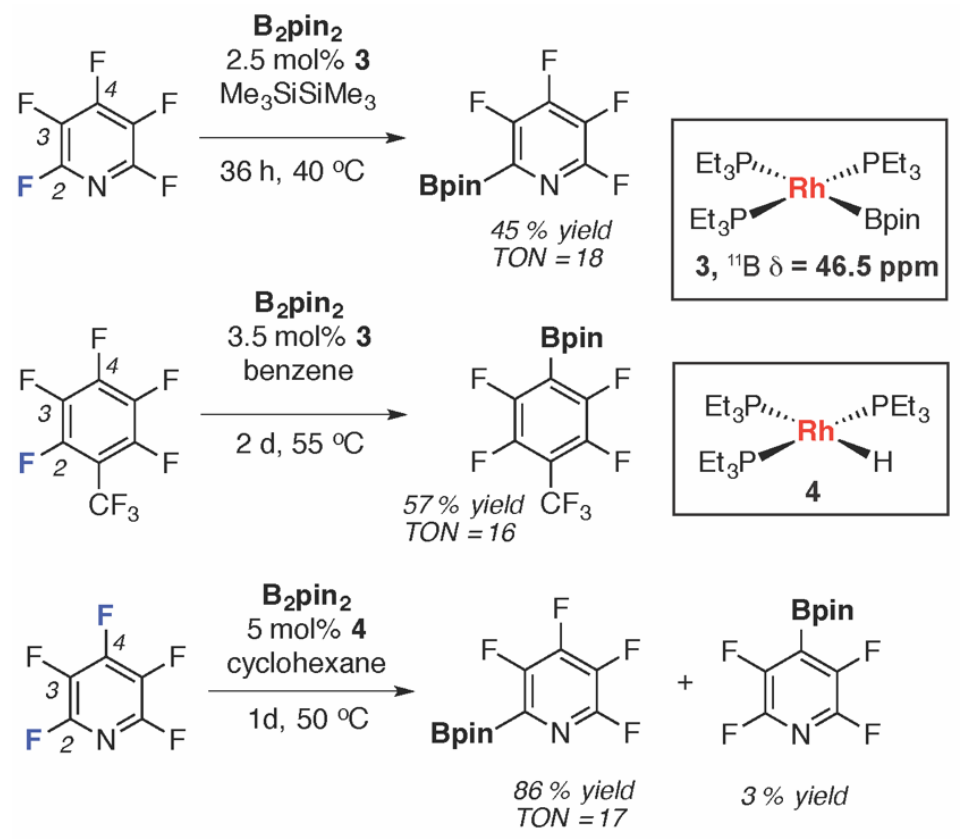

In search of a deeper understanding of the new reactivity and an explanation for the unusual regioselectivity, calculations were performed to compare two potential mechanisms for $\mathrm{C}-\mathrm{F}$ bond cleavage: (i) oxidative addition and (ii) $\sigma$-bond metathesis mechanism involving addition of the carbon-fluorine bond across the rhodium-boron bond. The second mechanism, boryl-assisted C$\mathrm{F}$ bond cleavage, parallels a proposed pathway for $\mathrm{C}-\mathrm{H}$ borylation using rhodium catalysts in a higher oxidation state. ${ }^{24,25}$ Perutz and others that have also demonstrated addition of the carbonfluorine bond across a $\left\{\mathrm{M}-\mathrm{PR}_{3}\right\}$ moiety. ${ }^{26}{ }^{27}$ Of the fpossible isomeric transition states considered for $\mathrm{C}-\mathrm{F}$ cleavage, the boryl-assisted TS was shown to have the lowest energy (Figure 2.3). While this result provides a satisfactory explanation for the observed regioselectivity, full exploration of each of the steps in the proposed catalytic cycle has not been reported at this time.

Figure 2.3. Origin of selectivity: Boryl-assisted carbon-fluorine bond cleavage

$$
\begin{gathered}
\text { Oxidative Addition } \\
\Delta \mathrm{E}^{*}=+\mathbf{4 6 . 9} \mathrm{kJ} \mathrm{mol}^{-1}
\end{gathered}
$$

\section{Boryl-Assisted}

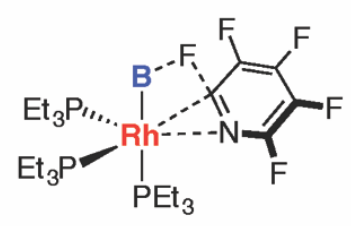

$\Delta \mathrm{E}^{+}=+17.2 \mathrm{~kJ} \mathrm{~mol}^{-1}$ 
More recently, Braun and coworkers have extended the study to include the reaction of $\mathbf{3}$ with series of perfluorinated and partially fluorinated aromatics under both catalytic and stoichiometric conditions. $^{28}$ Perfluorinated substrates, such as octafluorotoluene and hexafluorobenzene, undergo carbon-fluorine borylation while inclusion of any hydrogen atoms results in a switch in chemoselectivity and again exclusive reaction of the carbon-hydrogen bonds. For example, reaction of 3 with $\mathrm{C}_{6} \mathrm{~F}_{5} \mathrm{H}, 1,2,3-\mathrm{C}_{6} \mathrm{~F}_{3} \mathrm{H}_{3}, 1,3-\mathrm{C}_{6} \mathrm{~F}_{2} \mathrm{H}_{4}$ and $3,5-\mathrm{C}_{5} \mathrm{~F}_{2} \mathrm{H}_{3} \mathrm{~N}$ results in carbon-hydrogen bond activation with formation of new rhodium arene complexes from the breaking of a carbonhydrogen bond flanked by two fluorine atoms. ${ }^{28}$ The authors developed a catalytic $\mathrm{C}-\mathrm{H}$ borylation protocol for partially fluorinated aromatics based on these observations.

Carbon-fluorine borylation of octafluorotoluene occurred exclusively at the 4-position and could be catalysed by $3.5 \mathrm{~mol} \% 3$ leading to a TON of 16 . Despite the potential for carbon-hydrogen bond borylation, the authors demonstrate that the reaction tolerates deuterated benzene as a solvent - if borylation of the solvent is occurring in this system it must be at a slower rate than the fluorocarbon. This result is comparable to a TON of 17 recorded for pentafluoropyridine using cyclohexane as a solvent (Figure 2.2). While the activity is very similar to that reported when using hexamethyldislane as a solvent, in this case, small amounts of the regioisomeric product from reaction at the 4-position are observed.

Control reactions showed that $\left[\mathrm{Rh}(\mathrm{H})\left(\mathrm{PEt}_{3}\right)_{3}\right]$ (4) known to form from reaction of the rhodium(I) boryl with aromatic solvent, is catalytically competent for the $\mathrm{C}-\mathrm{F}$ borylation of $\mathrm{C}_{5} \mathrm{~F}_{5} \mathrm{~N}$ with 2 equiv. HBpin albeit over the course of 3 weeks at $25{ }^{\circ} \mathrm{C}$. In contrast to the previous data, the reaction occurs selectively at the 4-position. Further controls show that stepwise hydrodefluorination of pentafluoropyridine followed by carbon-hydrogen bond borylation is a viable pathway for the net C-F borylation reaction (Figure 2.4). ${ }^{28}$

Figure 2.4. Rhodium catalysed C-F borylation of pentafluoropyridine with HBpin

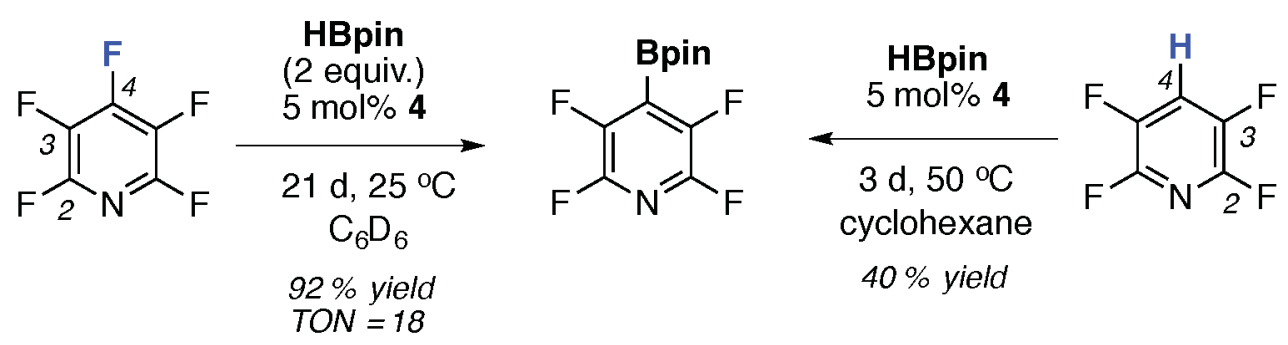

The first procedure for carbon-fluorine bond borylation with a broad substrate scope, tolerance of carbon-hydrogen bonds and further application in synthesis was reported in 2015 by Zhang and coworkers. ${ }^{29}$ Inclusion of a pyridyl-functional group in the substrate results in direction of the catalyst to the adjacent carbon-fluorine bond and ortho-selective borylation. Reactions proceed at 
$80-120{ }^{\circ} \mathrm{C}$ in toluene solvent using 2 equiv. $\mathrm{B}_{2} \mathrm{pin}_{2}, 2$ equiv. $\mathrm{KOAc}$ and $5 \mathrm{~mol} \%\left[\mathrm{Rh}(\operatorname{cod})_{2}\right] \mathrm{BF}{ }_{4}$. While the borylation of 2-pyridylpentafluorobenzene occurs efficiently under these conditions it is worth noting that small amounts of diborylation (a problem well established during carbonhydrogen bond functionalization) and hydrodefluorination were observed during catalyst screening.

The substrate scope includes a broad number of examples with varying levels of fluorination on the aromatic ring (Figure 2.5). Tolerance of carbon-oxygen, carbon-nitrogen bonds, sulphurcontaining or nitrogen-containing heterocycles is reported provided they are remote from the location of the directing group. While quinoline and benzoxazole directing groups may also be used instead of the 2-pyridyl group, the reaction is not tolerant of a carbon-hydrogen bond in the ortho-position. In the latter case low yields of $\mathrm{C}-\mathrm{F}$ borylation are reported due to competitive $\mathrm{C}-\mathrm{H}$ borylation. The reaction yields systematically decrease with lower levels of fluorination of the aromatic and the protocol appears to become increasingly inefficient for substrates bearing two ortho-fluorines $(60 \%$ yield) and one ortho-fluorine $(22-43 \%$ yield). To demonstrate utility, the authors prepared a iridium tris(chelate) relevant to photoelectronic materials using a product of C$\mathrm{F}$ borylation as a starting material. ${ }^{29}$

Figure 2.5. Directing group assisted rhodium-catalysed $\mathrm{C}-\mathrm{F}$ borylation of aromatic $\mathrm{sp}^{2} \mathrm{C}-\mathrm{F}$ bonds

Directing group:

pyridine, quinoline benzoxazole

$\mathrm{B}_{2} \operatorname{pin}_{2}$

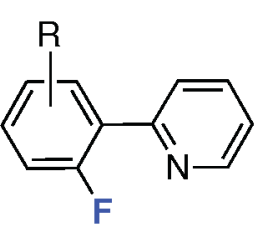

1-5 fluorine atoms

phenyl (2 equiv.)

KOAC

( 2 equiv.)

$5 \mathrm{~mol} \%$ $\left[\mathrm{Rh}(\mathrm{COD})_{2}\right] \mathrm{BF}_{4}$

toluene, $12-24 \mathrm{~h}$

$40-120^{\circ} \mathrm{C}$

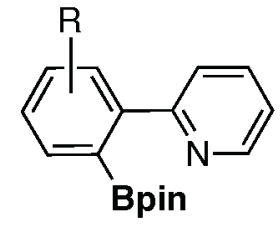

23 examples

$22-90 \%$ yield

biphenyl

heteroaromatic

The preliminary experiments on this system reveal very little about the reaction mechanism. The authors conclude that the most likely mechanism involves a $\mathrm{Rh}(\mathrm{III}) / \mathrm{Rh}(\mathrm{V})$ cycle with the key step of oxidative addition breaking the carbon-fluorine bond. There is only limited precedent for the proposed stoichiometric steps for organometallic complexes in the proposed oxidation states and largely the conclusions rely on insight gained from studying the reactions of $\left[C p^{*} \operatorname{Rh}(B p i n)_{2}(H)_{2}\right]$ which may have limited relevance to the true catalytic system. Under catalytic conditions, the authors show that the initial ratio of diborane:rhodium is important. Both the solvent (toluene) and cyclooctadiene ligand undergo borylation during catalysis. Despite these findings, there is limited experimental evidence for a $\mathrm{Rh}(\mathrm{III}) / \mathrm{Rh}(\mathrm{V})$ cycle, a rhodium(III) hydride intermediate and the borylassisted carbon-fluorine bond cleavage as presented. The conclusion is drawn based on the 
observation that $\left[\mathrm{Cp}{ }^{*} \mathrm{Rh}(\mathrm{Bpin})_{2}(\mathrm{H})_{2}\right]$ catalyzes the $\mathrm{C}-\mathrm{F}$ borylation of 2-pyridylpentafluorobenzene albeit with an efficiency lower than that of the true catalytic mixture.

\subsection{Nickel Catalysis}

In 2015 , the same year that rhodium systems were rendered catalytic for substrates bearing a directing group, two groups independently reported that the $\mathrm{C}-\mathrm{F}$ borylation of monofluoroarenes could be catalyzed by a combination of nickel(0) precursor, tricyclohexylphosphine ligand and additives. $^{30,31}$ The breakthroughs were quickly followed by a report by Marder, Radius and coworkers of nickel bis(N-heterocyclic carbene) catalysed carbon-fluorine borylation of partially fluorinated arenes. ${ }^{32}$ To date none of the nickel systems known are capable of the efficient borylation of perfluorinated arenes, they all require at least one carbon-hydrogen bond to be present in the substrate.

Martin and coworkers reported the C-F borylation of monofluoroarenes with bis(neopentylgylcolato)diborane could be mediated by 5 mol\% $\left[\mathrm{Ni}(\mathrm{COD})_{2}\right], 20 \mathrm{~mol} \% \mathrm{PCy}_{3}$ and 3 equiv. of $\mathrm{NaOPh}$ in $\mathrm{THF}$ at $110{ }^{\circ} \mathrm{C} .{ }^{30}$ Control experiments demonstrated that all the components were required for any conversion to the desired product. Optimisation of the conditions showed that the reaction was highly sensitive to the borane reagent, being inefficient for bis(pinacolato)diborane. Furthermore, the uncommon $4: 1$ ratio of ligand:metal and the use of a nickel cyclooctadiene precatalyst were essential for high catalyst activity. Preparations employing $\mathrm{Ni}(\mathrm{II})$ precatalysts or $\left[\mathrm{Ni}\left(\mathrm{PCy}_{3}\right)_{2}\right]_{2} \mathrm{~N}_{2}$ proved less effective than the optimised catalyst. The authors document a procedure with wide scope without compromising efficiency and scalability. Reactions could be performed on a gram scale and the scope includes substrates that contain non-reactive $\mathrm{C}-\mathrm{OSiR}$, C-OMe, C-NMe $2, \mathrm{C}_{-}-\mathrm{CF}_{3},-\mathrm{C}(\mathrm{O}) \mathrm{NR}_{2}$ and Bpin groups. Importantly the tolerance of an existing boronic ester group opens up the possibility of stepwise functionalization reactions using multiple halogen sites. Although the substrate scope can be forced beyond extended $\pi$-conjugated systems found in biaryls and naphthalene substrates, a doubling of the catalyst loading to $10 \mathrm{~mol} \%$ metal is required to achieve reasonable isolated yields of fluorobenzenes. ${ }^{30}$ 
Figure 2.6. Nickel-catalysed $\mathrm{C}-\mathrm{F}$ borylation of aromatic $\mathrm{sp}^{2} \mathrm{C}-\mathrm{F}$ bonds with $\mathrm{B}_{2} \mathrm{nep}_{2}$

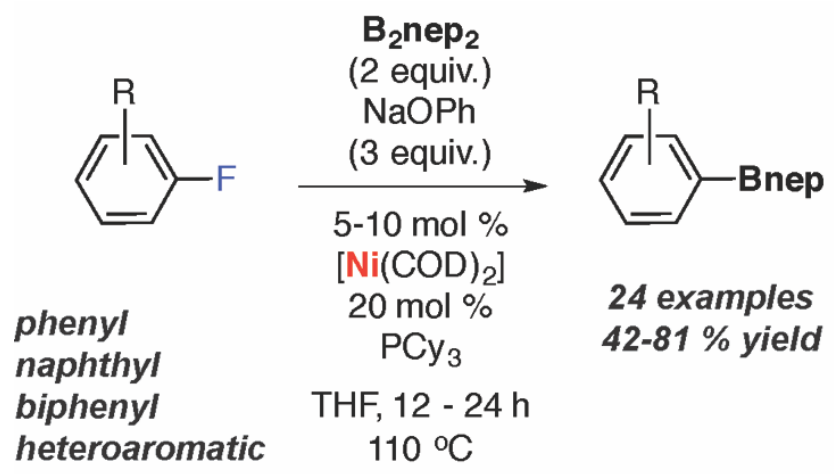

Currently, the authors favour a pathway involving $\mathrm{Ni}(0) / \mathrm{Ni}(\mathrm{II})$ with carbon-fluorine bond activation occurring by oxidative addition to an electron-rich low valent nickel fragment. There is experimental support for the hypothesis. Radius, and others, have shown that in situ generated two-coordinate $\mathrm{Ni}(0)$ bis(phosphine) or bis( $\mathrm{N}$-heterocyclic carbene) complexes are capable of the oxidative addition of carbon-fluorine bonds of polyfluorinated aromatics such as tetrafluorobenzene, hexafluorobenzene and ocatfluorotoluene. ${ }^{33-38}$ Martin and coworkers report the first example of the oxidative addition of a monofluoroaromatic, 1-fluoronapthalene upon reaction with a 1:2 mixture of $\left[\mathrm{Ni}(\mathrm{COD})_{2}\right]$ and $\mathrm{PCy}_{3}$ to form trans-[Ni(PCy$\left.)_{2}(\mathrm{~F})\left(\mathrm{C}_{10} \mathrm{H}_{7}\right)\right](5)$. While this complex was not isolated and fully characterized, and independent synthesis from the corresponding chloride provides significant support for its formulation. Reaction of 5 with $\mathrm{B}_{2} \mathrm{nep}_{2}$ and $\mathrm{NaOPh}$ yields the corresponding boronic ester. The sodium phenoxide base is proposed to play a role in boryl transfer. Despite these intriguing findings, numerous questions about the mechanism remain open; the strong dependence of the catalytic protocol to the ligand : metal ratio and presence of COD requires explanation as do details of the reductive elimination and turnover limiting steps in the putative cycle. ${ }^{30}$

Subsequent to this report, Hosoya and coworkers communicated a closely related catalyst system for the same transformation. ${ }^{31}$ The work included demonstration of synthetic utility. By exploiting further reactions of boronic esters that form carbon- ${ }^{18}$ fluorine, carbon-oxygen, carbon-carbon, carbon-halogen and carbon-nitrogen bonds, the authors were able to elegantly showcase the potential for late-stage carbon-fluorine bond functionalization in synthesis. Like the work reported by Martin and coworkers the authors screen reaction conditions using 4-fluorobiphenyl as a substrate, unlike the previous work they find that using $\mathrm{B}_{2} \mathrm{pin}_{2}$ as a stoichiometric reagent (2 equiv.) is possible for catalytic reactions using a combination of $10 \mathrm{~mol} \% \mathrm{Ni}(\mathrm{COD})_{2}, 50 \mathrm{~mol} \% \mathrm{PCy}_{3}, 20$ mol\% Cul and 2.4 equiv. CsF in toluene solvent at $80^{\circ} \mathrm{C}$. Control reactions with $\mathrm{B}_{2} \mathrm{nep}_{2}$ as the borane reagent gave poor results as did reactions in which non-anhydrous sources of fluoride were used. The optimized reaction conditions were applied to a series of electron-rich monofluorobiaryls bearing electron-donating groups at the 4'-position, and provided a three-fold increase in nickel, 
copper, phosphine and cesium fluoride loading is used, monofluoroaryls. While the protocol tolerates existing carbon-oxygen, carbon-nitrogen bonds and $\mathrm{N}$-containing heterocycles, the presence of any electron-withdrawing group such as esters or trifluoromethyl completely shuts down catalysis. ${ }^{31}$

Figure 2.7. Nickel/Copper-catalysed C-F borylation of aromatic $\mathrm{sp}^{2} \mathrm{C}-\mathrm{F}$ bonds with $\mathrm{B}_{2} \mathrm{pin}_{2}$

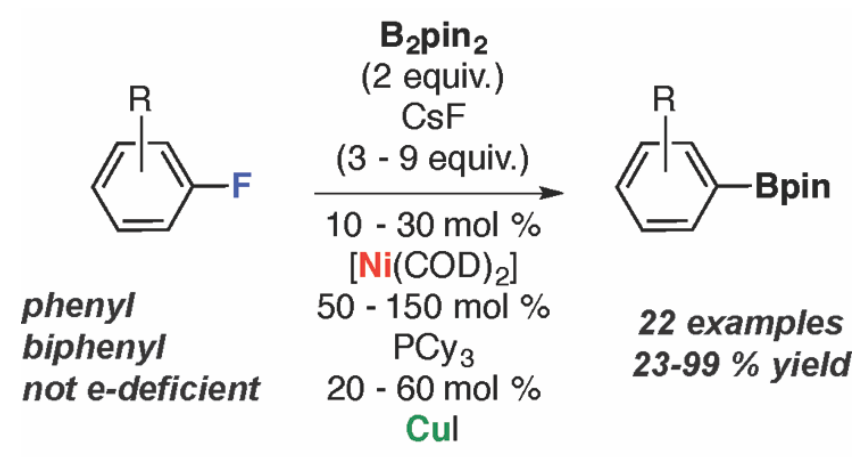

Toluene, $80^{\circ} \mathrm{C}, 24 \mathrm{~h}$

The authors suggest that the lack of appreciable reactivity for electron-deficient aromatics is not consistent with an oxidative addition mechanism. Using point kinetics (6 data points), an induction period is recorded for catalysis, although preconditioning of the catalyst, i.e mixing the components of the catalyst and ageing before addition to the reaction mixture, returns some activity at earlier time points. Single electron transfer (SET) is strongly disfavoured by radical trap experiments in which either 3,5-Di-tert-butyl-4-hydroxytoluene or 9,10-dihydroanthracene were added as radical scavengers. In combination with the bias in substrate scope, these experiments lead the authors to conclude that a $\mathrm{Ni}(\mathrm{I}) / \mathrm{Ni}(\mathrm{II})$ cycle may be operating. The copper(I) salt is proposed to oxidise $\mathrm{Ni}(0)$ to $\mathrm{Ni}(\mathrm{I})$ and carbon-fluorine bond activation to occur through the reaction of a putative $\mathrm{Ni}(\mathrm{I})$ boryl intermediate with the aryl fluoride. Currently little is known about the coordination sphere of nickel in these systems. The authors do demonstrate that a mixture of $\mathrm{Ni}(0)$ and $\mathrm{Ni}(\mathrm{II})$ salts can be used to achieve catalysis, suggesting that comproportionation may occur to form an active $\mathrm{Ni}(\mathrm{l})$ species. The approach is elegant but undermined by the need to still perform the reaction in the presence of Cul. ${ }^{31}$

In 2016, Marder, Radius and coworkers reported the C-F borylation of partially fluorinated aromatics using a less complex catalyst, $\left[\mathrm{Ni}(\mathrm{IMes})_{2}\right] .{ }^{32}$ The key point of novelty over the work published in 2015 is that, in this instance, the scope is not limited to monofluoroarenes. The reaction results in the production of fluorinated building blocks from partially fluorinated substrates. Radius and coworkers have previously shown that carbon-fluorine bond activation can occur by oxidative addition to $\left[\left\{\left({ }^{i} \operatorname{Pr}_{2} \mathrm{I}\right)_{2} \mathrm{Ni}\right\}_{2} \mathrm{COD}\right] .{ }^{38}$ In the current case, [Ni(IMes) $\left.)_{2}\right]$ was found to be more stable than the less sterically shielded analogue under the catalytic reaction conditions. A 
procedure was developed using 1 equiv. of substrate, 1 equiv. of $\mathrm{B}_{2} \mathrm{pin}_{2}, 10 \mathrm{~mol} \%$ [Ni(IMes) $)_{2}$ and 1 equiv. $\mathrm{CsF}$ or 0.5 equiv. of $\mathrm{NMe}_{4} \mathrm{~F}$ and methylcyclopentane as a solvent. The substrate scope reported to date, includes only fluorinated benzenes and the functional group tolerance is as yet unclear. In all cases the regioselectivity is such that the major isomer formed is that in which the Bpin group ends up adjacent to an existing carbon-hydrogen bond. The reaction is unsuccessful for perfluorinated substrates such as hexafluorobenzene. ${ }^{32}$ For pentafluorobenzene, $\left[\mathrm{Ni}(\mathrm{IMes})_{2}\right]_{2}$ proved ineffective as a catalyst but $\left[\mathrm{Ni}(\operatorname{IPr})_{2}\right]$ could be used in its place. In parallel with previous reports in this area the $\mathrm{C}-\mathrm{F}$ borylation protocol becomes decreasingly efficient with lower fluorine content of the aromatic ring. Preparations employing 1,2-difluorobenzene, 1,3-difluorobenene or fluorobenzene only proceed to $20-35 \%$ yield (Figure 2.8 ). In some cases, minor amounts of double substitution to form difunctionalised products is observed.

Figure 2.8. Nickel-catalysed C-F borylation of $\mathrm{sp}^{2} \mathrm{C}-\mathrm{F}$ bonds of partially fluorinated aromatics with $\mathrm{B}_{2} \mathrm{pin}_{2}$

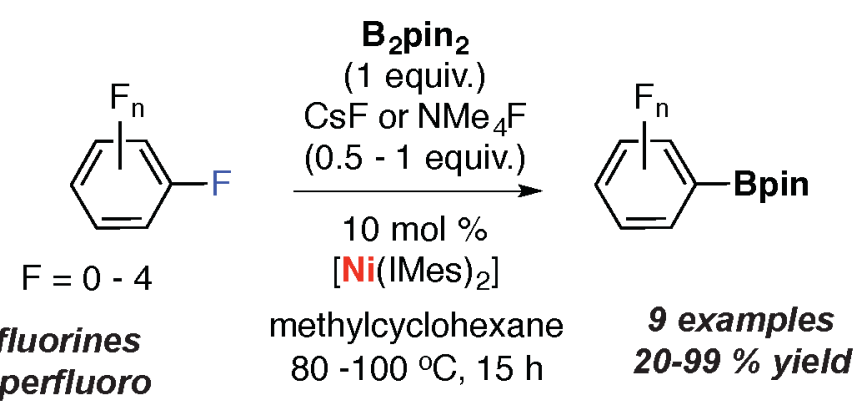

1-5 fluorines

Regioselectivity $(n=2-4)$
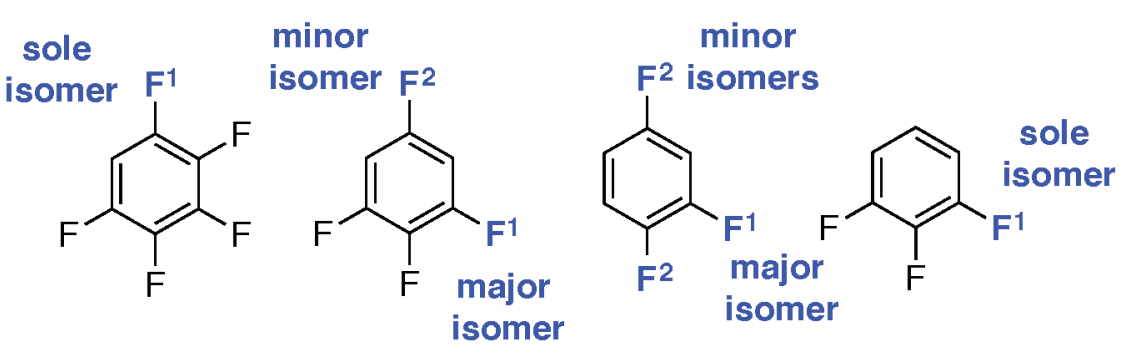

While the redox neutral $\mathrm{Ni}(\mathrm{I})$-boryl pathway suggested by Hosoya and coworkers, remains a mechanistic possibility, the authors suggest a $\mathrm{Ni}(0) / \mathrm{Ni}(\mathrm{II})$ cycle which parallels that proposed by Martin and coworkers. The hypothesis is strongly founded upon early contributions to this field. ${ }^{36-38}$ The reaction of $\left[\mathrm{Ni}(\mathrm{IMes})_{2}\right]_{2}$ with 1,2,4,5-tetrafluorobenzene proceeds rapidly and quantitively to give the expected square planar $\mathrm{Ni}(\mathrm{II})$ fluoride trans-[Ni(IMes) $\left.)_{2}(\mathrm{~F})\left(\mathrm{C}_{6} \mathrm{~F}_{3} \mathrm{H}_{3}\right)\right]$ a species that has been observed under catalytic conditions. The latter complex in turn reacts with $\mathrm{B}_{2} \mathrm{pin}_{2}$ in the presence of CsF to give the desired boronic ester. The CsF is suggested to facilitate boryl transfer by generation of a borate complex and ultimately provide a thermodynamic driving force due to the formation of $\mathrm{Cs}\left[\mathrm{F}_{2} \mathrm{Bpin}\right]$. While the origin of the regioselectivity is less clear, the authors suggest that reversible carbon-hydrogen bond activation may play a role in directing the catalyst to an adjacent $\mathrm{C}-\mathrm{F}$ bond. ${ }^{32}$ An alternative explanation exists which does not involve breaking of the carbon-hydrogen bond: the selectivity for the formation of $\pi$-complexes of partially fluorinated 
arenes is usually that in which the bound $\pi$-bond contains the fewest fluorine atoms. Typically this isomer is more stable as the geometry minimises electrostatic repulsion between the non-bonding electrons of fluorine and filled d-orbitals of the metal (Figure 2.9). ${ }^{26}$

Figure 2.9. Plausible origins for the selectivity of $\mathrm{C}-\mathrm{F}$ Borylation

\section{Reversible Carbon-Hydrogen Bond Activation}<smiles>Fc1ccc(F)c(F)c1F</smiles>

\section{$\pi$-Complex Formation}<smiles>Fc1ccc(F)c(F)c1F</smiles>

\section{C-F Alumination of $s p^{2} \mathrm{C}-\mathrm{F}$ Aromatic and $s p^{3} \mathrm{C}-\mathrm{F}$ Aliphatic Bonds}

In 2012, our group discovered a method to selectively hydrodefluorinate fluoroarenes with zirconocene-based catalysts. ${ }^{39}$ While the pioneering work of Jones and others had shown that zirconium hydride complexes are excellent reagents for carbon-fluorine bond activation, ${ }^{40}$ catalytic turnover in these systems was rare due to the high $\mathrm{Zr}-\mathrm{F}$ bond dissociation energy. ${ }^{19}$ By employing aluminium hydride reagents, we showed that catalyst turnover could be achieved. Control reactions revealed facile exchange of both fluoride and hydride ligands between aluminium and zirconium. We postulated that this ease of ligand exchange in combination with the thermodynamic driving force of forming a new Al-F bond allowed turnover in this system. As part of these studies we observed a series of byproducts that resulted from transformation of the carbon-fluorine bond into a new carbon-aluminium bond. The new reaction, carbon-fluorine alumination, is theoretically close to $100 \%$ atom efficient producing only dihydrogen as the byproduct and is represented in equation 6 in Figure 1.2. ${ }^{39}$

For example, heating a mixture of $6, \mathrm{C}_{6} \mathrm{~F}_{5} \mathrm{H}$ and $5 \mathrm{~mol} \%\left[\mathrm{Cp}_{2} \mathrm{ZrCl}_{2}\right]$ in $\mathrm{C}_{6} \mathrm{D}_{6}$ for $24 \mathrm{~h}$ at $80{ }^{\circ} \mathrm{C}$ results ing the formation of a $1.4: 1$ mixture of $\mathrm{C}-\mathrm{F}$ alumination $(7)$ and hydrodefluorination $\left(\mathrm{C}_{6} \mathrm{~F}_{4} \mathrm{H}_{2}\right)$ products respectively. The former was characterised by ${ }^{19} \mathrm{~F}$ NMR including ${ }^{19} \mathrm{~F}-{ }^{19} \mathrm{~F}$ and ${ }^{19} \mathrm{~F}-{ }^{1} \mathrm{H}$ correlation experiments along with mass spectrometry. Ultimately the assignment was confirmed by an independent synthesis (vide infra). While hexafluorobenzene also gave a mixture of products under these conditions more electron-deficient substrates such as octafluorotoluene and pentafluoropyridine yielded almost exclusively hydrodefluorination products. It is clear that substrate control is important in determining the chemoselectivity of this reaction and it remains 
likely that more than one mechanism may be in operation with the ease of hydride attack on the aromatic ring determining the ratio of hydrodefluorination : $\mathrm{C}-\mathrm{F}$ alumination.

Modification of the catalyst changed the regioselectivity of the reaction. Hence, heating a mixture of $6, \mathrm{C}_{6} \mathrm{~F}_{5} \mathrm{H}$ and $5 \mathrm{~mol} \%\left[\mathrm{Cp}{ }^{*} \mathrm{RhCl}(\mu-\mathrm{Cl})\right]_{2}$ in $\mathrm{C}_{6} \mathrm{D}_{6}$ for $24 \mathrm{~h}$ at $80{ }^{\circ} \mathrm{C}$ results in the formation of a mixture of hydrodefluorination products along with the aluminium complex 8. ${ }^{41}$ The carbonfluorine bond that reacts is that which is adjacent to an existing carbon-hydrogen bond and the regioselectivity complements that observed with zirconocene based catalysts.

Figure 3.1. Catalytic $\mathrm{C}-\mathrm{F}$ alumination of $\mathrm{sp}^{2} \mathrm{C}-\mathrm{F}$ bonds with an aluminium dihydride

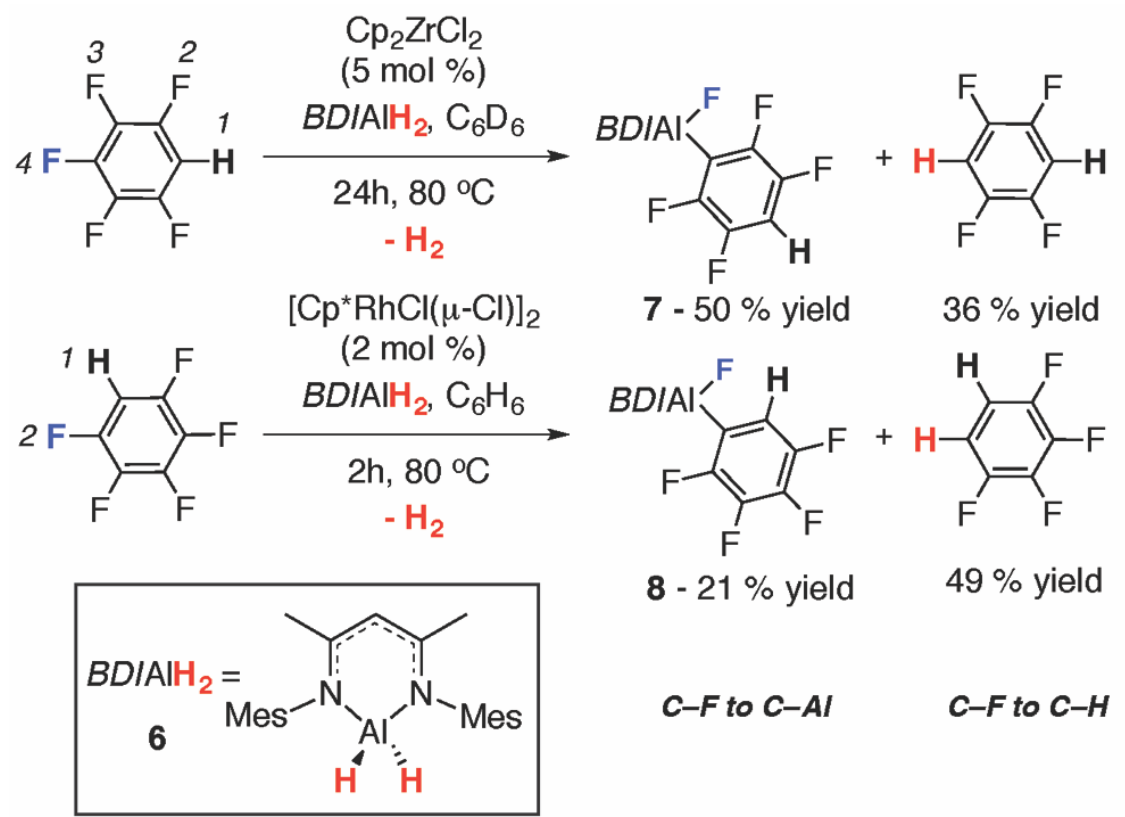

While the mechanism(s) of carbon-fluorine bond activation, including the unusual switch in regiochemistry are still not fully resolved, a series of experiments have been conducted that highlight at least two mechanisms that may be operating. Jones and coworkers have demonstrated that $\left[\mathrm{Cp}_{2} \mathrm{ZrH}_{2}\right]_{2}$ reacts with hexafluorobenzene to give a mixture of HDF and $\mathrm{C}-\mathrm{F}$ zirconation products, ${ }^{42}$ a mixture that is formed in a similar ratio to that observed under catalytic conditions. Reaction of this mixture with 6 results in reformation of the zirconocene hydride and transfer of the aryl group and fluoride to aluminium. Further investigation of the reactivity of aluminium hydrides coordinated to transition metals has raised the possibility of an in situ generation of $\mathrm{Al}(\mathrm{I})$ from hydride transfer to the transition metal and dehydrogenation of $6 .{ }^{43}$

In an attempt to exclude the involvement of $\mathrm{Al}(\mathrm{I})$ intermediates, control reactions were conducted between fluorocarbons and the only monomeric $\mathrm{Al}(\mathrm{I})$ complex devoid of $\mathrm{Al}-\mathrm{Al}$ bonds, $9{ }^{44}$ These experiments resulted in the discovery of facile oxidative addition of both $\mathrm{sp}^{2} \mathrm{C}-\mathrm{F}$ bonds of 
fluoroarenes and the $\mathrm{sp}^{3} \mathrm{C}-\mathrm{F}$ bonds of alkyl fluorides to $\mathrm{Al}(\mathrm{I})$ to form the previously observed organometallic products. ${ }^{45}$ The experimental data allow the unambiguous assignment of the complexes observed as part of mixtures under catalytic conditions.

The first example of oxidative addition of carbon-fluorine bonds to $\mathrm{Al}(\mathrm{I})$ by our group was made almost contemporaneously with a closely related study by Nikonov and coworkers. ${ }^{46}$ In combination the papers show that, while the oxidative addition reaction currently has a modest substrate scope, the types of $\mathrm{C}-\mathrm{F}$ bond that react are quite diverse relative to the other examples presented herein. The reaction encompasses fluoroarenes with 3-6 fluorine atoms present and both primary and secondary alkyl fluorides. The results are noteworthy as examples of oxidative addition of $\mathrm{sp}^{3} \mathrm{C}-\mathrm{F}$ bonds to any metal are exceptionally rare. Increasingly harsh conditions are required for oxidative addition of trifluoro- and tetrafluorobenzenes relative to pentafluoro- and hexafluorobenzene. For example, while addition of $\mathrm{C}_{6} \mathrm{~F}_{6}$ to 9 is proposed to proceed at temperatures as low as $-60{ }^{\circ} \mathrm{C}$, the reaction of $1,2,3-\mathrm{C}_{6} \mathrm{~F}_{3} \mathrm{H}_{3}$ with the same reagent requires $96 \mathrm{~h}$ at $80^{\circ} \mathrm{C}$ to produce a $3: 1$ mixture of regioisomeric oxidative addition products (Figure 3.2). In general, the regioselectivity is such that the major site of reaction is the carbon-fluorine bond flanked by two ortho-fluorine substituents. While our group showed that the reactions proceed to $93-99 \%$ yield as evidence by ${ }^{1} \mathrm{H}$ NMR spectroscopy by comparison against an internal standard, Nikonov and coworkers reported isolated yields of crystalline organometallic products that range between 55 $71 \%$, with the exception of the reaction with $1,3,5-\mathrm{C}_{6} \mathrm{~F}_{3}$ for which limited data was recorded.

Figure 3.2. Oxidative addition of $\mathrm{sp}^{2} \mathrm{C}-\mathrm{F}$ and $\mathrm{sp}^{3} \mathrm{C}-\mathrm{F}$ bonds to $\mathrm{Al}(\mathrm{I}) .{ }^{\mathrm{a}} \mathrm{NMR}$ scale yields in parantheses.<smiles>Fc1cccc(F)c1F</smiles>
$\mathrm{n}=2-5$

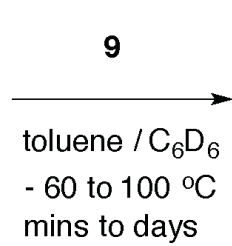

mins to days

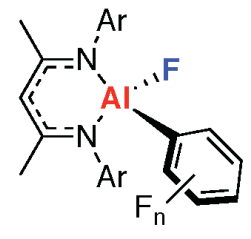

5 examples $55-71(99 \%)^{a}$ yield

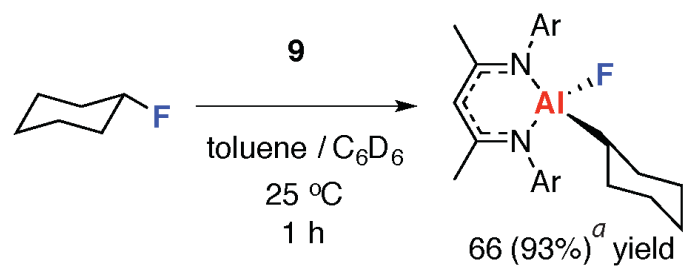<smiles>[R]CCCCCF</smiles>

$\mathrm{R}=\mathrm{H}, \mathrm{Me}$

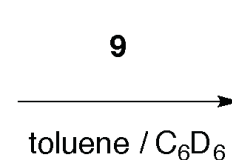
$25^{\circ} \mathrm{C}$ $1 \mathrm{~h}$

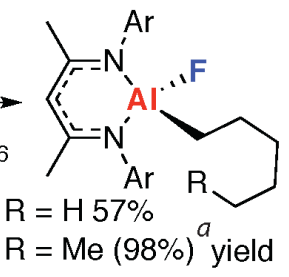

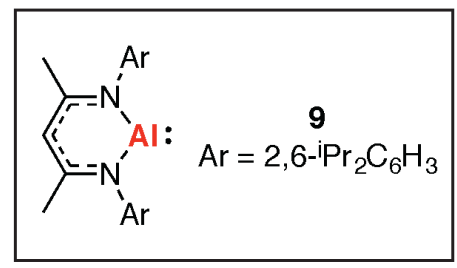

Regioselectivity ( $n=2-4$ )

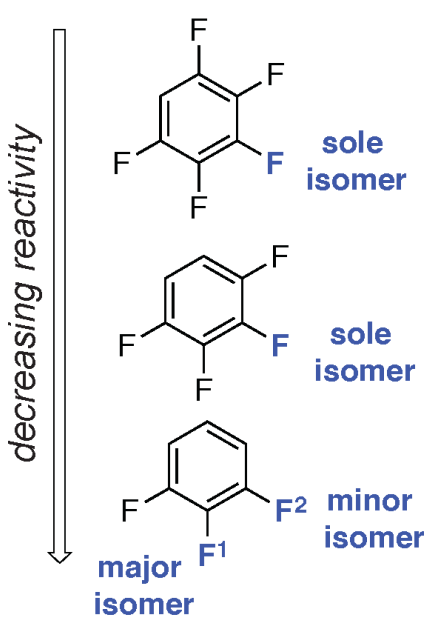


Nikonov and coworkers investigated the kinetics of the reaction of 9 with 1,2,4,5tetrafluorobenzene under pseudo-first order conditions. The empirical rate law was found to be second order overall, first order in fluoroarene and first order in $\mathrm{Al}(\mathrm{I})$. In combination with, the experimental activation parameters of $\Delta \mathrm{H}^{\ddagger}=57.1(2) \mathrm{kJ} \mathrm{mol}^{-1}$ and $\Delta \mathrm{S}^{\ddagger}=-113.6(3) \mathrm{J} \mathrm{K}^{-1} \mathrm{~mol}^{-1}$, these data suggest a concerted reaction involving a highly ordered transition state.

\section{C-F Silylation and Germylation of Aromatic $s^{2} \mathrm{C}-\mathrm{F}$ Bonds}

In 1998, Murai and coworkers reported silicon-fluorine exchange in fluorobenzenes catalysed by cationic rhodium complexes. ${ }^{47}$ The reaction takes inspiration from the same groups pioneering work in $\mathrm{C}-\mathrm{H}$ alkenylation ${ }^{48}$ and relies on a suitable directing group (ketone, oxazoline) in the substrate to direct the catalyst to the ortho-position. For example, the reaction of pentafluoroacetophenone and $\mathrm{Me}_{3} \mathrm{Si}-\mathrm{SiMe}_{3}$ catalyzed by $10 \mathrm{~mol} \%\left[\mathrm{Rh}(\mathrm{COD})_{2}\right] \mathrm{BF}_{4}$ in toluene at $130{ }^{\circ} \mathrm{C}$ yields the corresponding aryl silane and $\mathrm{Me}_{3} \mathrm{Si}-\mathrm{F}$ (Figure 4.1). While a key break through in the field, the reaction is extremely limited in scope, confined to three examples all of which bear no ortho- $\mathrm{C}-\mathrm{H}$ bonds presumably due to the potential for competitive $\mathrm{C}-\mathrm{H}$ functionalization. Control reactions demonstrated that the directing group was essential for activity with hexafluorobenzene only giving trace conversion under the same conditions. ${ }^{47}$ In the case of the oxazoline derived substrate catalytic C-F bond silylation at a single site was accompanied by modest amounts of both double addition and hydrodefluorination. The hydrogen atom source for the hydrodefluorination reaction is not clear but may arise from proteodesilylation.

Figure 4.1. Directing group assisted rhodium-catalyzed C-F silylation<smiles>[X]c1c([X])c(F)c(C(C)=O)c(F)c1[X]</smiles>

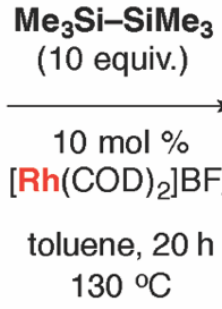

toluene, $20 \mathrm{~h}$ $130^{\circ} \mathrm{C}$

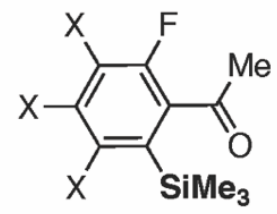

$$
\begin{gathered}
X=F, 79-88 \% \\
X=H, 33 \%
\end{gathered}
$$
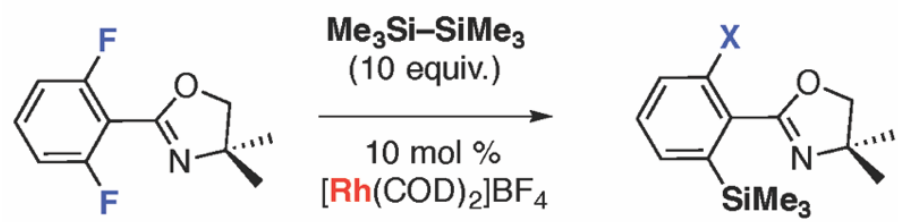

toluene, $40 \mathrm{~h}$ $130^{\circ} \mathrm{C}$

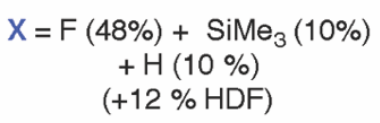


In 2010, Herbert Roesky and coworkers reported the activation of $\mathrm{sp}^{2} \mathrm{C}-\mathrm{F}$ bonds of a series of perfluoroarenes and the selective activation of the $\mathrm{sp}^{2} \mathrm{C}-\mathrm{F}$ bond of pentafluorobenzene by oxidative addition to silicon(II) complexes (Figure 4.2). ${ }^{49}$ Two well-defined silylene complexes were used, a two-coordinate species support by a dianoinic $N, N$-chelating ligand 10 and a threecoordinate complex bearing an amidinate and chloride ligand 11. Oxidative addition of the carbonfluorine bond to the silicon(II) centres proceed cleanly and give the corresponding four- and fivecoordinate silicon fluoride complexes in $70-88 \%$ isolated yield. The substrate scope includes octafluorotoluene, hexafluorobenzene and pentafluoropyridine and the regiochemistry is consistent with that expected for nucleophilic addition $\left(S_{N} A r\right)$ to these electron-deficient aromatics. For pentafluorobenzene, competitive $\mathrm{C}-\mathrm{H}$ and $\mathrm{C}-\mathrm{F}$ bond activation is observed and variation of the silylene allows control over the chemoselecitivity, while 10 reacts with the carbon-hydrogen bond 11 reacts exclusively with the carbon-fluorine bond.

Figure 4.2. Oxidative Addition of $\mathrm{sp}^{2} \mathrm{C}-\mathrm{F}$ bonds to $\mathrm{Si}(\mathrm{II})$ and $\mathrm{Ge}(\mathrm{II})$

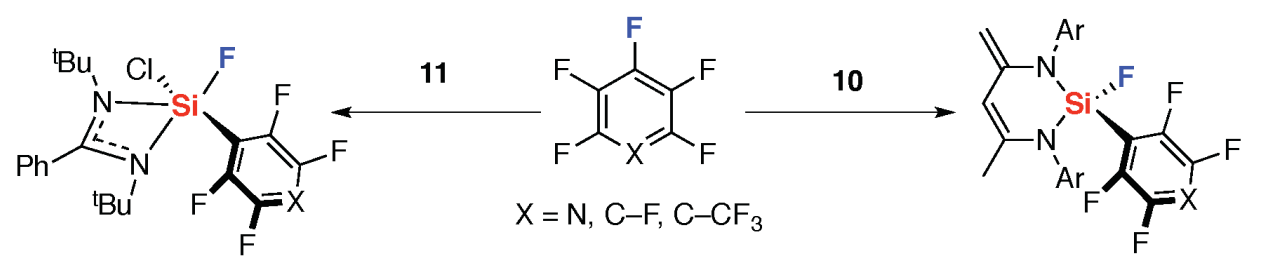

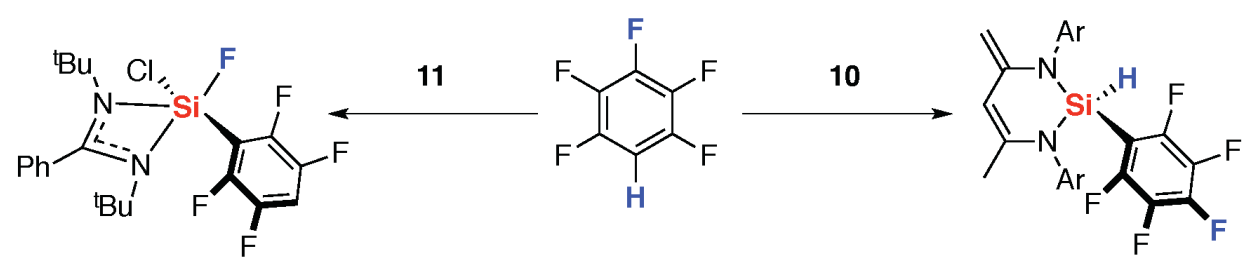<smiles>CN(C)c1c(F)c(F)nc(F)c1F</smiles>

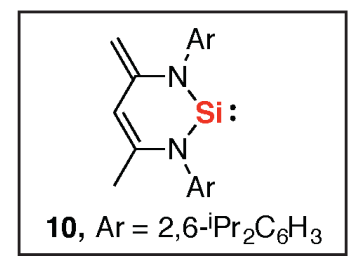<smiles></smiles>

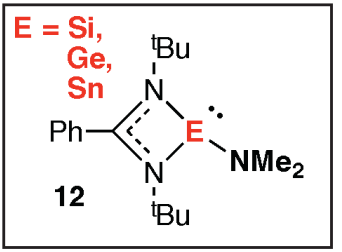

The observation of oxidative addition of carbon-fluorine bonds to $\mathrm{Si}(\mathrm{II})$ is unsurprising based on precedent set in carbene chemistry, addition of fluorinated arenes to N-heterocyclic carbenes and cyclic amino alkyl carbenes is known. ${ }^{50,51} 52$ While the same group demonstrated that the three coordinate germylene $\mathbf{1 2}$ also react with pentafluorobenzene to cleave the carbon-fluorine bond, attempts to extend the chemistry to tin(II) proved unsuccessful. ${ }^{53}$ For example, reaction of the $\mathrm{Sn}$ analogue of 12 with $\mathrm{C}_{6} \mathrm{~F}_{5} \mathrm{H}$ leads to a metathesis reaction and formation of the corresponding 
$\mathrm{Sn}$ (II) fluoride and 4- $\mathrm{Me}_{2} \mathrm{NC}_{6} \mathrm{~F}_{4} \mathrm{H}$, a likely manifestation of the inert pair effect and the increased stability of tin complexes in the +2 oxidation state. The understanding of the reaction mechanism for carbon-fluorine bond cleavage with silylenes or germylenes remains somewhat opaque, although there are likely parallels with the chemistry described for $\mathrm{Al}(\mathrm{I})$.

\section{C-F Magnesiation of Aromatic $\mathrm{sp}^{2} \mathrm{C}-\mathrm{F}$ Bonds}

In 2016, our group reported the 1,2-addition of the carbon-fluorine bond of fluoroarenes across the $\mathrm{Mg}-\mathrm{Mg}$ bond of a hydrocarbon soluble $\mathrm{Mg}(\mathrm{I})$ reagent (equation 3, Figure 1.2). ${ }^{54,55}$ The reaction parallels the use of diboranes, $R_{2} B-B R_{2}$ and disilanes $R_{3} S i-S_{R} R_{3}$ in $C-F$ functionalization chemistry but unlike these latter systems no catalyst is required for carbon-fluorine bond cleavage. The reaction does not rely on expensive or toxic transition metals and can be achieved with a single main group metal.

Although addition of $\mathrm{C}_{6} \mathrm{~F}_{6}$ to 13 results in facile carbon-fluorine bond cleavage. The reaction scope includes a number of partially fluorinated and perfluorinated arenes (Figure 5.1). The reaction byproduct is a dimeric magnesium fluoride $[B D / M g(\mu-F)(T H F)]\left({ }^{19} \mathrm{~F} N M R \delta=-188 \mathrm{ppm}\right)$. The two reaction products could be separated by fractional crystallisation of the fluoride complex followed by removal of the solvent. While likely unnecessary for the development of further reactions, the separation allowed the isolation and characterization of the reactive organometallic products including the first crystallographic characterization of magnesium fluoroaryl complexes.

For perfluoroarenes in the majority of cases a single reaction product is observed and the regioselectivity parallels well established patterns established throughout this review. For partially fluorinated arenes such as pentafluorobenzene, 1,2,3,4-tetrafluorobenzene and 1,2,3,5tetrafluorobenzene, two regioisomeric products were observed. In these cases, reactions occur at the carbon-fluorine bond with two ortho-fluorine substituents. ${ }^{56}$ In combination with the data collected on the $\mathrm{AI}(\mathrm{I})$ system, the data suggest that the ortho-fluorine effect ${ }^{26,57}$ well established in carbon-hydrogen bond activation and rationalised based upon the impact of the adjacent fluorine atoms on the $\mathrm{C}-\mathrm{H}$ and $\mathrm{C}-\mathrm{M}$ bond strengths may be in operation for carbon-fluorine bond

activation. ${ }^{58} 59$ For the two partially fluorinated aromatics with the most acidic carbon-hydrogen bonds small amounts 5-20 \% of C-H bond functionalization were observed to be competitive with carbon-fluorine bond activation. 
Figure 5.1. Oxidative Addition of $\mathrm{sp}^{2} \mathrm{C}-\mathrm{F}$ bonds to a $\mathrm{Mg}(\mathrm{I})-\mathrm{Mg}(\mathrm{I})$ bond. NMR scale yields in parentheses.
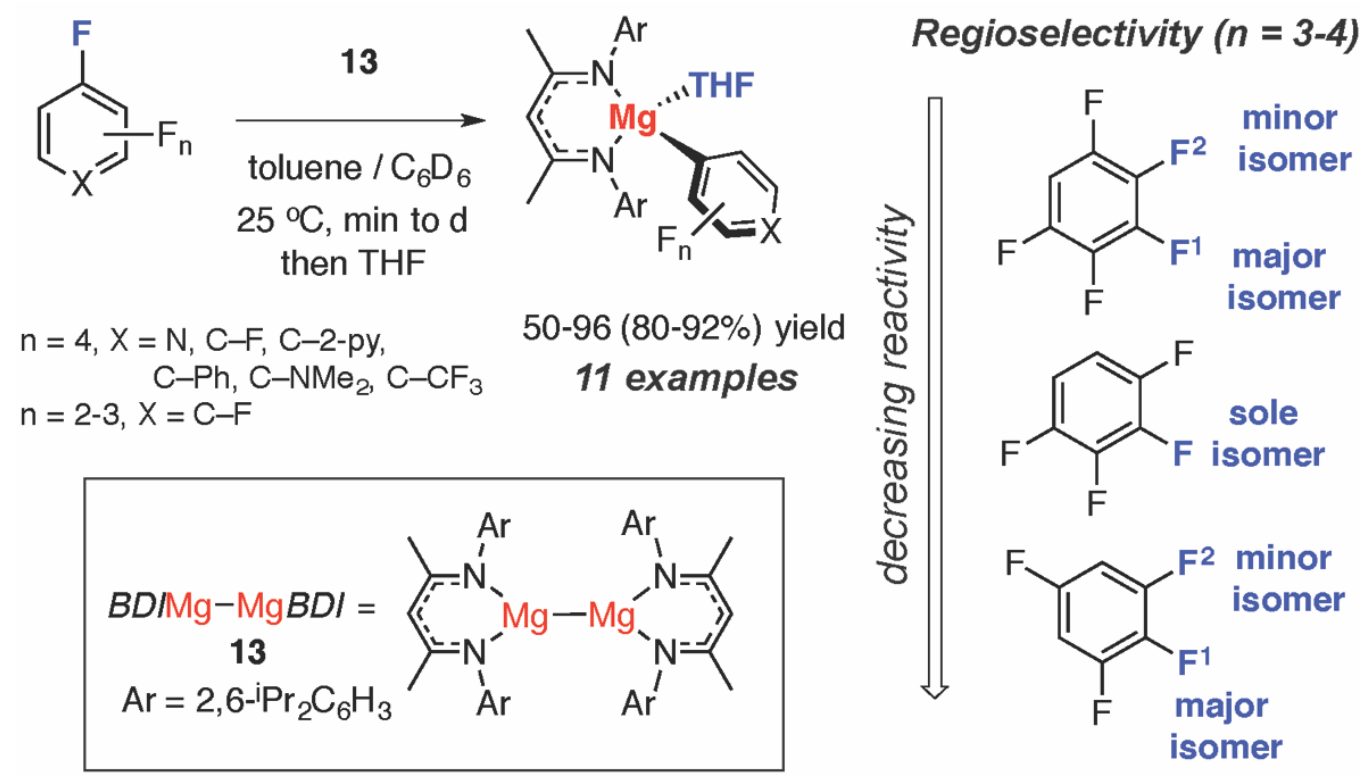

Preliminary mechanistic experiment suggest that the reaction may be concerted and unlikely to involve long-lived radical intermediates. The dissociation of 13 into two magnesium radicals [BD/Mg] has been calculated to be exergonic by approx. $45 \mathrm{kcal} \mathrm{mol}^{-1}$ and unlikely to occur under the mild reaction conditions. ${ }^{60} 61$ A cross-over experiment employing two different $\mathrm{Mg}(\mathrm{I})-\mathrm{Mg}(\mathrm{I})$ reagents, however, allowed the isolation of an asymmetric $\mathrm{Mg}(\mathrm{I})-\mathrm{Mg}(\mathrm{I})$ complex. While this result could be interrupted as a result of homolysis of the $\mathrm{Mg}-\mathrm{Mg}$ bond it could also be explained by exchange of the $\{\mathrm{Mg}-\mathrm{Mg}\}^{2+}$ core between the anionic ligands. Further radical trapping experiments with 9,10-dihydroanthracene or 1,4-cyclohexadiene show no effect on the efficiency of C-F magnesiation. Given the ease in which these substrates undergo $\mathrm{C}-\mathrm{H}$ abstraction, the data suggest that neither organic nor organometallic radicals are reaction intermediates. ${ }^{54}$

\section{C-F Silylation and Borylation of Alkenes}

While the functionalization of the $\mathrm{sp}^{2} \mathrm{C}-\mathrm{F}$ bonds of alkenes is less studied than that of aromatics, Braun and coworkers have reported a series of protocols for the defluorination and hydrosilylation or hydroborylation of hexafluoropropene. ${ }^{62,63}$ For example, the catalytic conversion of hexafluoropropene into 3,3,3-trifluoropropylsilanes can be achieved by reactions with aryl-, alkylor alkoxy-silanes catalyzed by either $\left[\mathrm{Rh}(\mathrm{H})\left(\mathrm{PEt}_{3}\right)_{3}\right](4)$ or $\left[\mathrm{Rh}\left(\mathrm{Z}-\mathrm{CF}=\mathrm{CFCF}_{3}\right)\left(\mathrm{PEt}_{3}\right)_{3}\right](14)$. The latter complex is formed from the stoichiometric reaction of $\left[\mathrm{Rh}(\mathrm{H})\left(\mathrm{PEt}_{3}\right)_{3}\right]$ with hexafluoropropene in the presence of triethylamine. ${ }^{64}$

Although carbon-fluorine bond activation is limited to a single substrate, a number of silanes can be employed including triphenylsilane, triethylsilane and trimethoxysilane. The reaction byproduct 
is the silyl fluoride and a $4: 1$ silane:fluorocarbon reaction stoichiometry is required. Optimised turnover numbers range from 12-90, with triphenylsilane providing the most reactive catalytic system and trimethoxysilane requiring the addition of a base to reach the highest catalyst performance. The overall reaction represents a hydrodefluorination and silylation of the alkene, removing three fluorine atoms and replacing them with four hydrogen atoms and a silyl group while reducing the alkene to an alkane. Substitution of the silane for HBpin resulted in the development of a similar catalytic net $\mathrm{C}-\mathrm{F}$ borylation reaction of hexafluoropropene. In this case multiple products are observed, including different regioisomers in addition to double-addition products which include two Bpin units. Hence, reaction of hexafluoropropene with an excess of HBpin catalysed by $0.4 \mathrm{~mol} \%\left[\mathrm{Rh}(\mathrm{H})\left(\mathrm{PEt}_{3}\right)_{3}\right]$ yields a 3:1:6 mixture of 15:16:17. Despite the known reactivity toward hydrocarbons, no borylation of the aromatic solvent was observed.

Figure 6.1. Reductive silylation and borylation of hexafluoropropene (catalyst loading based on 4 equiv. of main group reagent)
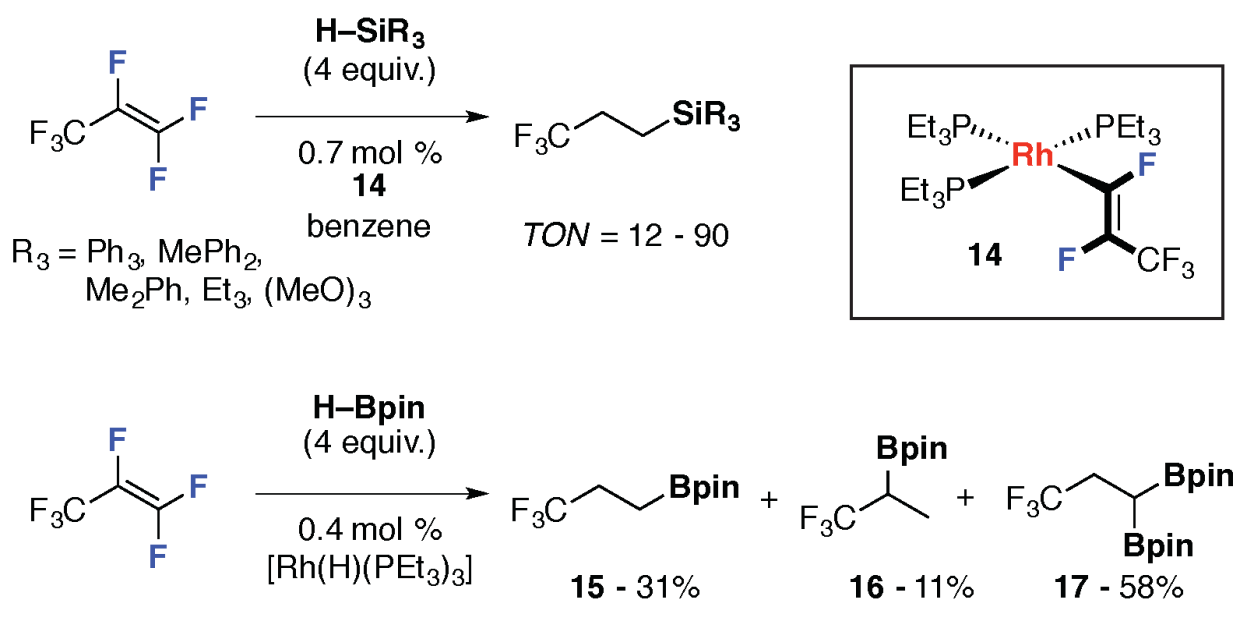

While a number of pathways can be envisioned to achieve the transformations outlined above. The authors suggest that the hydrosilylation or hydroboration of 3,3,3-trifluoroproprene is an important step. A hypothesis that is confirmed by a control experiment in which this latter substrate is shown to undergo hydrosilylation under catalytic conditions to yield the corresponding 3,3,3trifluoropropylsilane. While 3,3,3-trifluoropropene may again be employed using HBpin as a terminal reagent the selectivity is significantly different for this substrate compared to hexafluoropropene. A network of pathways can be envisioned to explain the data, including: (i) hydrodefluorination to form 3,3,3-trifluoropropene followed by alkene hydroborylation I hydrosilylation, (ii) $\mathrm{C}-\mathrm{F}$ borylation / silylation with subsequent alkene hydrogenation, (iii) $\mathrm{C}-\mathrm{F}$ borylation followed by hydroborylation of the alkene and (iv) hydrodefluorination to form 3,3,3trifluoropropene followed by stepwise hydroboration-dehydrogenation-hydroboration. The latter two pathways both explain the products of double addition observed with HBpin. 


\section{Conclusions and Future Directions}

In summary, in the past few years a number of methods to functionalise carbon-fluorine bonds with main group reagent have emerged. To date, carbon-fluorine bond borylation is the most studied, and based on the broad known applications of boronic esters, arguably the most promising approach. Nevertheless, expensive (rhodium) or toxic (nickel) catalysts are required to effect the borylation of $\mathrm{sp}^{2} \mathrm{C}-\mathrm{F}$ bonds often at high catalyst loadings. As a complementary approach the oxidative addition of fluorocarbons to low-valent $\mathrm{Al}(\mathrm{I}), \mathrm{Mg}(\mathrm{I})-\mathrm{Mg}(\mathrm{I}), \mathrm{Si}(\mathrm{II})$ and $\mathrm{Ge}(\mathrm{II})$ centres has emerged, while both $\mathrm{sp}^{2} \mathrm{C}-\mathrm{F}$ and $\mathrm{sp}^{3} \mathrm{C}-\mathrm{F}$ bonds are known to participate in these reactions it is clear that significant developments will need to be made to elaborate further reactivity of the organometallic products of these reactions.

Given the persistence of fluorocarbons in the environment, the near complete absence of naturally occurring organic fluorides and the continued expansion of the fluorochemicals market, it is clear that $\mathrm{C}-\mathrm{F}$ functionalization is an important approach not only for synthesis but also for chemical recycling. The vast majority of naturally occurring fluorine is in the form of inorganic salts including fluorite $\left(\mathrm{CaF}_{2}\right)$ and cryolite $\left(\mathrm{Na}_{3} \mathrm{AlF}_{6}\right)$. The reactions reported herein result in the transformation of fluorocarbons into reactive chemical building blocks with formation of new $\mathrm{B}-\mathrm{F}, \mathrm{Al}-\mathrm{F}, \mathrm{Si}-\mathrm{F}, \mathrm{Ge}-\mathrm{F}$ or $\mathrm{Mg}-\mathrm{F}$ bonds, returning at least a small component of the fluorine content to an inorganic molecule.

Carbon-fluorine bond functionalization has potential not only as a method for late-stage derviatisation of fluorine containing molecules, for example drug candidates or agrochemicals, but also the upgrading of simple fluorochemicals to form reactive building blocks. Ideal methods for late-stage functionalization should be functional group tolerant and attractive targets include the transformation of $\mathrm{C}-\mathrm{F}$ bonds into $\mathrm{C}-{ }^{18} \mathrm{~F}$ for medical imaging or $\mathrm{C}-\mathrm{CF}_{3}$ or $\mathrm{C}-\mathrm{CF}_{2} \mathrm{H}$ bonds as means to vary the properties of trial candidates at a late-stage.

Methods to upgrade simple fluorocarbons such as fluoroarenes, fluoroalkenes and fluoroalkanes do not need to be functional group tolerant but will require the development of more efficient catalysts and increased scope. While methods to activate $\mathrm{sp}^{2} \mathrm{C}-\mathrm{F}$ bonds of arenes have now emerged, the most environmentally damaging use of fluorocarbons is arguably of hydrofluorocarbons (HFCs) as refrigerants. New methods to activate $\mathrm{sp}^{3} \mathrm{C}-\mathrm{F}$ bonds would allow wider use of simple HFCs as chemical building blocks, this remains a challenge for the field. 


\section{References}

1 C. Isanbor and D. O'Hagan, J. Fluorine Chem., 2006, 127, 303-319.

2 S. Purser, P. R. Moore, S. Swallow and V. Gouverneur, Chem. Soc. Rev., 2008, 37, 320-330.

3 D. O. Hagan, J. Fluorine Chem., 2010, 131, 1071-1081.

4 D. O'Hagan and H. S. Rzepa, Chem. Commun., 1997, 645-652.

5 D. O'Hagan, Chem. Soc. Rev., 2008, 37, 308-319.

6 C. N. Neumann and T. Ritter, Angew. Chem., Int. Ed., 2015, 54, 3216-3221.

7 M. G. Campbell and T. Ritter, Chem. Rev., 2015, 115, 612-633.

8 D. Lentz, T. Braun and M. F. Kuehnel, Angew. Chem., Int. Ed., 2013, 52, 3328-3348.

9 T. Ahrens, J. Kohlmann, M. Ahrens and T. Braun, Chem. Rev., 2015, 115, 931-972.

10 S. Preshlock, M. Tredwell and V. Gouverneur, Chem. Rev., 2016, 116, 719-766.

11 T. Liang, C. N. Neumann and T. Ritter, Angew. Chem., Int. Ed., 2013, 52, 8214-8264.

12 R. D. Fowler, W. B. Burford III, J. M. Hamilton Jr, R. G. Sweet, C. E. Weber, J. S. Kasper and I. Litant, Ind. Eng. Chem., 1947, 39, 292-298.

13 V. D. Shteingarts, J. Fluorine Chem., 2007, 128, 797-805.

14 G. Meier and T. Braun, Angew. Chem., Int. Ed., 2009, 48, 1546-1548.

15 H. Amii and K. Uneyama, Chem. Rev., 2009, 109, 2119-2183.

16 T. G. Driver, Angew. Chem., Int. Ed., 2009, 48, 7974-7976.

17 A. D. Sun and J. A. Love, Dalton Trans., 2010, 39, 10362-10374.

18 T. Braun and F. Wehmeier, Eur. J. Inorg. Chem., 2011, 613-625.

19 M. Klahn and U. Rosenthal, Organometallics, 2012, 31, 1235-1244.

20 M. K. Whittlesey and E. Peris, ACS Catal., 2014, 4, 3152-3159.

21 J.-Y. Cho, C. N. Iverson and M. R. Smith III, J. Am. Chem. Soc., 2000, 122, 12868-12869.

22 R. J. Lindup, T. B. Marder, R. N. Perutz and A. C. Whitwood, Chem. Commun., 2007, 36643666.

23 M. Teltewskoi, J. A. Panetier, S. A. Macgregor and T. Braun, Angew. Chem., Int. Ed., 2010, 49, 3947-3951.

24 J. F. Hartwig, K. S. Cook, M. Hapke, C. D. Incarvito, Y. Fan, C. E. Webster and M. B. Hall, J. Am. Chem. Soc., 2005, 127, 2538-2552.

25 C. S. Wei, C. A. Jiménez-Hoyos, M. F. Videa, J. F. Hartwig and M. B. Hall, J. Am. Chem. Soc., 2010, 132, 3078-3091.

26 E. Clot, O. Eisenstein, N. Jasim, S. A. Macgregor, J. E. McGrady and R. N. Perutz, Acc. Chem. Res., 2011, 44, 333-348.

27 S. A. Macgregor, D. C. Roe, W. J. Marshall, K. M. Bloch, V. I. Bakhmutov and V. V. Grushin, J. Am. Chem. Soc., 2005, 127, 15304-15321.

28 S. I. Kalläne, M. Teltewskoi, T. Braun and B. Braun, Organometallics, 2015, 34, 1156-1169.

29 W.-H. Guo, Q.-Q. Min, J.-W. Gu and X. Zhang, Angew. Chem., Int. Ed., 2015, 127, 90759078.

30 X.-W. Liu, J. Echavarren, C. Zarate and R. Martin, J. Am. Chem. Soc., 2015, 137, 1247012473.

31 T. Niwa, H. Ochiai, Y. Watanabe and T. Hosoya, J. Am. Chem. Soc., 2015, 137, 1431314318.

32 J. Zhou, M. W. Kuntze-Fechner, R. Bertermann, U. S. D. Paul, J. H. J. Berthel, A. Friedrich, Z. Du, T. B. Marder and U. Radius, J. Am. Chem. Soc., 2016, 138, 5250-5253.

33 S. A. Johnson, C. W. Huff, F. Mustafa and M. Saliba, J. Am. Chem. Soc., 2008, 130, 1727817280

34 D. R. Fahey and J. E. Mahan, J. Am. Chem. Soc., 1977, 99, 2501-2508.

35 A. Arévalo, A. Tlahuext-Aca, M. Flores-Alamo and J. J. García, J. Am. Chem. Soc., 2014, 136, 4634-4639.

36 T. Schaub and U. Radius, Chem. Eur. J., 2005, 11, 5024-5030.

37 T. Schaub, M. Backes and U. Radius, J. Am. Chem. Soc., 2006, 128, 15964-15965.

38 T. Schaub, P. Fischer, A. Steffen, T. Braun, U. Radius and A. Mix, J. Am. Chem. Soc., 2008, 130, 9304-9317.

39 S. Yow, S. J. Gates, A. J. P. White and M. R. Crimmin, Angew. Chem., Int. Ed., 2012, 51, 12559-12563.

40 W. D. Jones, Dalton Trans., 2003, 3991-3995.

41 O. Ekkert, S. D. A. Strudley, A. Rozenfeld, A. J. P. White and M. R. Crimmin, 
Organometallics, 2014, 33, 7027-7030.

42 B. L. Edelbach, A. K. Fazlur Rahman, R. J. Lachicotte and W. D. Jones, Organometallics, 1999, 18, 3170-3177.

43 O. Ekkert, A. J. P. White, H. Toms and M. R. Crimmin, Chem. Sci., 2015, 6, 5617-5622.

44 C. Cui, H. W. Roesky, H.-G. Schmidt, M. Noltemeyer, H. Hao and F. Cimpoesu, Angew. Chem., Int. Ed., 2000, 39, 4274-4276.

45 M. R. Crimmin, M. J. Butler and A. J. P. White, Chem. Commun., 2015, 51, 15994-15996.

46 T. Chu, Y. Boyko, I. Korobkov and G. I. Nikonov, Organometallics, 2015, 34, 5363-5365.

47 Y. Ishii, N. Chatani, S. Yorimitsu and S. Murai, Chem. Lett., 1998, 27, 157-158.

48 S. Murai, F. Kakiuchi, S. sekine, Y. Tanaka, A. Kamatani, M. Sonoda and N. Chatani, Nature, 1993, 366, 529-531.

49 A. Jana, P. P. Samuel, G. Tavčar, H. W. Roesky and C. Schulzke, J. Am. Chem. Soc., 2010, 132, 10164-10170.

50 E. Mallah, N. Kuhn, C. Maichle-Mossmer, M. Steimann, M. Stobele and K.-P. Zeller, Z. Naturforsch., 2009, 64b, 1176-1182.

51 N. Kuhn, J. fahl, R. Boese and G. Henkel, Z. Naturforsch., 1998, 53b, 881-886.

52 Z. R. Turner, Chem. Eur. J., 2016, 22, 11461-11468.

53 P. P. Samuel, A. P. Singh, S. P. Sarish, J. Matussek, I. Objartel, H. W. Roesky and D. Stalke, Inorg. Chem., 2013, 52, 1544-1549.

54 C. Bakewell, A. J. P. White and M. R. Crimmin, J. Am. Chem. Soc., 2016, 12763-12766.

55 S. P. Green, C. Jones and A. Stasch, Science, 2007, 318, 1754-1757.

56 S. A. Macgregor, D. McKay, J. A. Panetier and M. K. Whittlesey, Dalton Trans., 2013, 42, 7386-10.

57 A. D. Selmeczy, W. D. Jones, M. G. Partridge and R. N. Perutz, Organometallics, 1994, 13, 522-532.

58 E. Clot, C. Mégret, O. Eisenstein and R. N. Perutz, J. Am. Chem. Soc., 2009, 131, 78177827.

59 M. E. Evans, C. L. Burke, S. Yaibuathes, E. Clot, O. Eisenstein and W. D. Jones, J. Am. Chem. Soc., 2009, 131, 13464-13473.

60 J. Overgaard, C. Jones, A. Stasch and B. B. Iversen, J. Am. Chem. Soc., 2009, 131, 42084209.

61 S. J. Bonyhady, S. P. Green, C. Jones, S. Nembenna and A. Stasch, Angew. Chem., Int. Ed., 2009, 48, 2973-2977.

62 T. Braun, F. Wehmeier and K. Altenhöner, Angew. Chem., Int. Ed., 2007, 46, 5321-5324.

63 T. Braun, M. A. Salomon, K. Altenhöner, M. Teltewskoi and S. Hinze, Angew. Chem., Int. Ed., 2009, 48, 1818-1822.

64 T. Braun, D. Noveski, B. Neumann and H.-G. Stammler, Angew. Chem., Int. Ed., 2002, 41, 2745-2748. 